\title{
BIOÉTICA Y JURISPRUDENCIA
}

\author{
Pedro Federico Hooft ${ }^{*}$
}

Resumen: El trabajo analiza, en la primera parte, los fuertes y estrechos vínculos existentes entre Bioética y Derecho desde los albores mismos del nacimiento de esta nueva transdisciplina, y el creciente entrelazamiento que se produce en las sociedades actuales entre Bioética, Medicina y Derecho. Relaciona este fenómeno tanto con la «medicalización de la vida», como con la «juridificación de la sociedad». En este contexto, se reconoce a la salud como un valor fundamental, reconocido y protegido por el Derecho, entendida la salud bioética y jurídicamente, y como necesario correlato del mismo derecho a la vida. Sentada esta premisa, el autor pasa revista al fenómeno de la progresiva «juridificación» de la Bioética, sin dejar de observar la ambivalencia de ese proceso, con sus luces y sus sombras. Propone articular Bioética y Derecho recurriendo a la filosofía de los derechos humanos como «puente» de comunicación entre ambos, y hace mención a la fructífera labor de la jurisprudencia argentina desarrollada en esa línea.

Palabras clave: Bioética y Derecho, transfusión de sangre, anencefalia, píldora del día después, transplante de órganos

\section{BIOETHICS AND JURISPRUDENCE}

\begin{abstract}
This work analyzes, in the first part, the close and strong existing bonds between Bioethics and Law from the same dawn of birth of this new interdisciplinary liason, and the growing interweaving that takes place in the scientific community between Bioethics, Medicine and Law. This phenomenon is related both to the "medicalization of life", and to the "juridification of the society". In this context, health is ethically and legally understood as a fundamental value, recognized and protected by the law, and necessarily grants the same to the right to life. Assuming this premise, the author reviews the phenomenon of the progressive "juridification" of Bioethics, without disregarding to observe the ambivalence of that process, with its lights and shadows. He proposes to articulate Bioethics and Law resorting to philosophy of the human rights as the "bridge of communication" between both, and mentions the fruitful work of Argentine jurisprudence developed in this line.
\end{abstract}

Key words: Bioethics and law, blood transfussion, anencephalic, day after pill, organ transplantation

\section{BIOÉTICA E JURISPRUDÊNCIA}

Resumo: O trabalho apresenta em sua primeira parte, os vínculos fortes e estreitos existentes entre Bioética e Direito desde o nascimento desta nova transdisciplina . Outrossim, mostra o crescente entrelaçamento observado nas sociedades atuais entre a Bioética, Medicina e Direito. Relaciona este fenômeno tanto com a "medicalização da vida" quanto com a “jurisdificação da sociedade". Nesse contexto, a saúde deve ser reconhecida como valor fundamental protegido pelo direito, considerando-a no prisma bioético e jurídico como expressão do direito a vida. Estabelecida essa premissa, o autor analisa o fenômeno da progressiva " jurisdificação" da bioética, sem deixar de salientar a ambivalência desse processo com suas luzes e sombras. Propõe articular Bioética e Direito recorrendo à filosofia dos direitos humanos como "parte" da comunicação entre ambas e apresenta o produtivo trabalho que a jurisprudência argentina desenvolve neste aspecto.

Palavra chave: Bioética e direito, transfusão de sangue, anencefalia, pílula do dia seguinte, transplante de órgãos

\footnotetext{
* Juez. Profesor Titular de Filosofía del Derecho y Miembro del Comité Académico de la carrera de Postgrado en Bioética en la Universidad Nacional de Mar del Plata. Presidente de la Asociación Argentina de Bioética

Correspondencia: hooftpf@infovia.com.ar
} 
"Los seres humanos son respetables porque son seres humanos, no porque tengan los mismos valores o compartan las mismas creencias"

\section{Diego Gracia Guillén(1)}

“...la Bioética puede transformarse en una auténtica herramienta para la convivencia significativa entre personas, ideologías, grupos y culturas."

Fernando Lolas Stepke(2)

\section{El entrelazamiento entre Bioética, Medicina y Derecho}

Desde sus propios comienzos, la Bioética se ha caracterizado por sus fuertes y estrechos vínculos con el Derecho. Las conexiones entre ambos afectan a las bases mismas de la vida social. El estudio de las interconexiones entre Bioética y Derecho revela que el marco jurídico lejos de presentarse como algo meramente externo a nuestra condición de sujetos de derecho, conforma a la realidad social misma. De allí que donde el Derecho "conforma" a la sociedad, nos "conforma" al mismo tiempo como miembros de esa sociedad, ya no como seres de la vida cotidiana sino "juridificados"(3).

No resulta aquí ocioso recordar que en la moderna doctrina del "consentimiento informado" convergen claramente, por un lado, un largo proceso de desarrollo iniciado en el campo del Derecho y, por el otro, los aportes provenientes desde la reflexión bioética, ahora con un claro anclaje en el respeto y dignidad personal, concebido entonces el "consentimiento informado", en el sentido de "regla", como expresión del principio bioético de "autonomía" o de "respeto por las personas" en la terminología del "Belmont Report"(4).
Durante el período de la génesis de la Bioética fueron teólogos, filósofos y estudiosos del campo de la medicina y del Derecho quienes, desde sus propios y específicos ámbitos disciplinarios, se ocuparon de los problemas éticos originados a causa del desarrollo de las ciencias biomédicas inicialmente, a las que pronto se sumarían los interrogantes suscitados en el área de la genética molecular y los referidos a los crecientes problemas medio ambientales. De esta manera, contribuyeron al surgimiento y ulterior expansión de la Bioética, -entre otros factores o acontecimientos-, la revolución biológica, la catástrofe ecológica y la medicalización de la vida, como fenómeno sociocultural que se caracteriza por la integración de un "bios tecnológico" y un "ethos secular", la tecnificación de la vida y la liberalización de la moral(5).

Sabemos que las sociedades actuales -en cuyo seno la tecnociencia ha introducido una profunda y vertiginosa transformación(6)- se caracterizan asimismo por la ya citada "medicalización de la vida", fenómeno asociado a una creciente y compleja "juridización de la sociedad"(7), y al creciente entrelazamiento entre Ética, Medicina y Derecho(8, 9).

En este contexto, la salud como valor fundamental, reconocido y protegido por el Derecho, entendida social, bioética y jurídicamente, pasa a ser un correlato necesario del mismo derecho a la vida(3).

En nuestras sociedades actuales, pluralistas y democráticas, la velocidad de los progresos biomédicos, las repercusiones sociales que plantea la atención de la salud, como son la accesibilidad, la justicia y la solidaridad, presentan apasionantes desafíos éticos. Sobre todo porque involucran el concepto mismo de ser humano que tenemos para nosotros mismos y para los demás, 
nuestro concepto de vida y de muerte, y nuestro criterio y prudencia para que los avances tecnológicos estén orientados al mejoramiento de la calidad de vida y de muerte, priorizando por sobre todo la idea y el valor de la dignidad humana -como individuo y como especie-, no sólo de las generaciones presentes sino también de las futuras, aunado al cuidado y protección del medio ambiente en un momento histórico en el cual los avances científico-tecnológicos ofrecen posibilidades inéditas, desconocidas en períodos históricos anteriores. Es en este nuevo contexto que se ha generado y desarrollado una nueva sensibilidad histórica, una creciente preocupación ética por la calidad de vida, en una inescindible relación con la idea de dignidad humana $(10,11)$.

A pesar de existir hoy día una general coincidencia en reconocer el fuerte entrelazamiento entre Ética, Medicina y Derecho -en estrecho contacto con las ciencias empíricas(12)-, varían los enfoques al momento de determinar cómo, y de qué manera, se articulan en situaciones concretas las diversas disciplinas involucradas en las complejas cuestiones bioéticas de nuestros días.

En ese contexto de "entrelazamiento", particularmente en los Estados Unidos de Norteamérica y, en menor medida, en la Bioética europea, se ha acentuado progresivamente el polo jurídico, no sólo en el ámbito de la discusión pública sino también en los espacios académicos. Una exteriorización de dicha tendencia la podríamos encontrar en la localización que en las grandes librerías del mundo occidental se asigna a los textos bioéticos los cuales, es ahora frecuente encontrar juntamente con las publicaciones de Derecho, cuando hasta hace no muchos años tales títulos solían hallarse en las secciones destinadas a la filosofía, a la medicina y a la ética médica(13). Se trata de un fenómeno que guarda relación coherente con la "juridificación de la sociedad" y con una creciente incorporación de los esquemas del pensamiento jurídico al planteo y solución de los problemas bioéticos.

La Bioética, que en sus primeras fases de desarrollo se forjó enfatizando los derechos individuales y el principio de autonomía, al extenderse e incorporarse a otros contextos culturales se vio favorecida por diálogos fructíferos, que mostraron una Bioética con una perspectiva más amplia, en la cual nuevas influencias sociales y culturales pasaron a formar parte del razonamiento ético(14).

\section{La Bioética y la necesidad de nuevas formas de juridicidad}

Resulta conocida la impronta de las doctrinas del "contractualismo social" y de las corrientes racionalistas-individualistas en el moderno proceso de codificación del Derecho, iniciado con la sanción del Código Civil francés de 1804, con fuertes huellas en todo el derecho privado continental posterior, no sólo europeo sino inclusive en nuestros países latinoamericanos. Esta codificación, que surgió para dar solución frente a una virtual anarquía legislativa y superposición y aun contradicción entre órdenes normativos de distinta proveniencia, asumió de hecho una fuerte orientación hacia los derechos patrimoniales, acorde con la ideología política predominante en el siglo XIX.

El "espíritu" de esa codificación, que se correspondió con la escuela francesa de la exégesis y la idea de Montesquieu acerca del juez como mera "boca de la ley", entró francamente en crisis en el pensamiento jurídico ya hacia fines del siglo XIX, con un giro definitivo que daría a esta visión positivista del Derecho la obra de François Geny y su propuesta superadora a favor de un método de "libre investigación científica". La continuación de nuevas líneas de apertura 
se vio rápidamente en el campo legislativo con la sanción, en el año 1900, del nuevo Código Civil alemán y, años después, con el Código Civil suizo de las Obligaciones.

Sin embargo, recién a mediados del siglo XX, bajo los impulsos del denominado "constitucionalismo social" y el desarrollo de los "derechos humanos de la segunda generación", se advierten tendencias -con su máxima expresión en las legislaciones europeooccidentales posteriores a la segunda guerra mundial-, que marcan una apertura hacia una juridicidad, ahora más atenta al bienestar de la persona, y con la recepción de los denominados "derechos personalísimos", en un tránsito desde el clásico estado liberal de derecho, al estado social y democrático de derecho(15).

Estos desarrollos favorecen el diálogo fructífero entre Bioética y Derecho, reconociendo en la filosofía de los derechos humanos una especie de hilo conductor, que remite a la dignidad personal como cristalización histórica de la conciencia ética de la $\operatorname{sociedad}(16)$.

Una explicitación de esa "nueva forma de juridicidad" en sociedades pluralistas y democráticas $^{1}$, pero a la vez respetuosas de la dignidad inalienable del ser humano, se ve claramente formulada en la Convención de Asturias (Convenio relativo a los Derechos Humanos y la Biomedicina) de 1997, más conocida como Convención Europea de Bioética.

Dicha convención ciertamente expresa sólidos lazos con un instrumento netamente jurídico como lo es la Convención Europea sobre Derechos y Libertades Fundamentales vínculos que también pueden hallarse con relación a la Convención Americana sobre Derechos Humanos de San José de Costas Rica de 1969-, desde que ambas convenciones comparten no solamente determinados lineamientos fundamentales, sino también los mismos principios éticos y las mismas nociones jurídicas. Sin embargo, del análisis comparativo de tales documentos fundacionales, surgen también notables diferencias, siendo éstas las que confieren a la Convención de Bioética sus peculiaridades distintivas: en ésta no se trata ya solamente del reconocimiento y protección de derechos y libertades fundamentales, sino de la clara afirmación de principios y valores en materia de la específica reafirmación de la dignidad humana como principio rector, en relación con el derecho a la identidad de cada ser humano (4, p. XXV/XXVII) $)^{2}$.

Este concepto o idea de "dignidad humana" cuenta con una fructífera tradición jurídica, especialmente en el campo de los "Derechos Humanos", de modo particular a partir de la Carta de la ONU y, luego, de la Declaración Universal de 1948 y todos los documentos internacionales y regionales posteriores. Pero esa misma idea, principio o valor, adquiere en el contexto bioético una peculiar significación, con mayor remisión a la tradición filosófica de la modernidad, y que aquí se traduce en la inadmisibilidad de toda forma de instrumentalización del ser humano en el campo de la biología y la medicina y en la absoluta primacía del ser humano respecto de los intereses económicos o del mero progreso

\footnotetext{
Este desarrollo referido a nuevas formas de juridicidad, siguen los lineamientos del texto de la exposición enviado para el "Sexto Congreso Mundial de Bioética", Brasilia, 30 de octubre al 3 de noviembre de 2002, de la International Association of Bioethics, para las sesiones principales (Mesas Redondas), sobre "Bioderecho: una crítica al neologismo", y al cual me remito.
} 
de la ciencia. Otro principio caro al derecho actual, como el de "no discriminación", adquiere en el campo de las ciencias bioéticas una nueva dimensión, tal como se pone de manifiesto, v.gr., en la Declaración Universal sobre Genoma Humano y los Derechos Humanos de la UNESCO de 1997, que proclama como principio rector del documento la esencial dignidad y unicidad de cada individuo humano, cualesquiera que sean sus características genéticas ${ }^{3}$.

Tanto el origen de este importante documento (al haber sido elaborado por el Comité Internacional de Bioética de la UNESCO) - luego aprobado por la Asamblea General de la institución y por la A.C. de la ONU por voto unánime de sus miembros-, como la materia abordada, tan sensible con relación a la dignidad personal y de la especie humana (con una proyección en cuanto a responsabilidad intergeneracional), lo pone, asimismo, en la línea de la mentada "nueva juridicidad", en un espacio de convergencia del Derecho en sentido clásico con los nuevos aportes interdisciplinarios provenientes de la Bioética.

En el ámbito americano, la Convención sobre Derechos Humanos aprobada en San José de Costa Rica en 1969 retoma y amplía la visión respetuosa de la dignidad humana ya contenidos en la Carta de la ONU y en la Declaración Universal de 1948. Así, en el Preámbulo del Pacto de San José de Costa Rica se reivindica la "dignidad esencial del ser humano" y los derechos fundamentales que le son inherentes como "atributos de la persona humana". De la correlación entre tan claros enunciados del Preámbulo y las disposiciones

\footnotetext{
3 Ver: Gross Espiell H. Más allá de la Declaración de la UNESCO sobre el Genoma Humano y los Derechos Humanos. Lexis Nexis Jurisprudencia Argentina. Número especial Bioética. Coord. Hooft PF. $1^{\text {a }}$ Parte 2001: 16-27.
}

de la parte sistemática de la Convención, se infiere que esa dignidad inalienable opera como valor fundante respecto de los diversos derechos fundamentales que la propia Convención consagra.

Las normas referidas al derecho a la vida, a la integridad personal, a la libertad personal, de protección de la honra y de la dignidad y de la protección judicial (entre otras), adquieren por cierto significativa importancia para el análisis y la toma de decisiones referidas a cuestiones bioéticas.

\section{III. ¿Cómo articular Bioética y Derecho?}

En una de las obras "fundacionales" de la Bioética en lengua española, Diego Gracia ${ }^{4}$, al desarrollar sus argumentos relacionados con una "Bioética mínima", plantea las relaciones peculiares entre Ética y Derecho. A ese respecto observa que si bien Ética y Derecho "son cosas distintas", se hallan, sin embargo, "internamente vinculadas". Respecto de la modalidad de dicha vinculación, su propuesta se orienta a respetar la autonomía de cada uno de los dos ámbitos, pero de manera tal "que permita su influencia recíproca: de la Ética como instancia crítica del Derecho y del Derecho como expresión positiva y práctica de la Ética".

El autor traslada el planteo referido a la Ética, a la Bioética, y del Derecho al "Bioderecho". Sin embargo, al desarrollar más en concreto el "cómo" de esa recíproca influencia, Diego Gracia no brinda una fundamentación particular respecto de la utilización del neologismo "Bioderecho", más

\footnotetext{
Gracia D. Fundamentos de Bioética Madrid: Editorial Eudema; 1989: 576. En un trabajo que publicara hace ya una década, personalmente adopté el esquema del maestro Diego Gracia, para referirme al "Bioderecho" en el sentido de la regulación jurídica de la problemática Bioética, perspectiva que replanteo en este trabajo.
} 
aún, por momentos habla indistintamente de "Derecho" o de "Bioderecho" en su relación con la Bioética, aunque cabe inferir del texto una utilización prevalente del término "Bioderecho" en su vínculo con la Bioética.

Dentro del pensamiento iusfilosófico y bioético argentino, ha sido Ciuro Caldani uno de los grandes impulsores del término "Bioderecho" al cual conceptualiza en el sentido de una "rama jurídica transversal" que no significa negación, pero sí complemento de otras ramas del Derecho ${ }^{5}$.

También en lengua portuguesa, hemos conocido publicaciones que abordan nuestra problemática bajo el título de "Bioderecho", como por ejemplo el de la jurista Sá(17). Paralelamente pareciera que las publicaciones efectuadas en español por parte de juristas que se han ocupado de la problemática bioética se habla de manera prevalente de "Bioética y Derecho", y no de "Bioética y "Bioderecho"

Otros autores en cambio colocan el acento en los rasgos jurídicos de la Bioética, dentro del ya mencionado fenómeno de

\footnotetext{
Ciuro Caldani MA. La elaboración de las normas del Bioderecho. Jurisprudencia Argentina. Número especial de Bioética. Buenos Aires 1998; 6113. El nombrado autor, docente e investigador de la Universidad de la ciudad de Rosario, dirige desde hace varios años la Revista Bioética y Bioderecho, que publica la Facultad de Derecho de la referida Facultad. En esta misma línea, puede mencionarse el libro de la docente e investigadora de la Universidad de Mar del Plata, Graciela N. Messina de Estrella Gutiérrez, cuyo libro Bioderecho aborda la problemática bioética, priorizando la perspectiva desde el derecho civil.

6 Valga como ejemplo paradigmático el excelente libro de Romeo Casabona C M. El derecho y la Bioética ante los límites de la vida humana. Madrid: Editorial Centro de Estudios Ramón Areces S.A.; 1994. En lengua italiana cabe mencionar, a modo de ejemplo, el libro de Calo E. Bioética. Nuevos derechos y autonomía de la voluntad. (Traducción de Luigi Di Vita Fornaciari). Buenos Aires: Ediciones La Rocca; 2000. Dentro de las publicaciones argentinas, se sigue análogo criterio, en el libro de Garay OE, coord. Responsabilidad Profesional de los Médicos. Ética, Bioética y Jurídica: Civil y Penal. Buenos Aires: Ed. La Ley; 2002.
}

"medicalización de la vida" y "juridización de la sociedad", destacando el nivel conceptual de congruencia entre el Derecho y la Medicina, que se hace cada vez más patente hoy día en las prácticas institucionales médicas y jurídicas $(14, p .28)$.

\section{Control de Constitucionalidad en el sistema jurídico institucional argentino}

Así como el desarrollo del derecho privado argentino, particularmente el derecho civil, siguió a partir de su codificación en la segunda mitad del siglo XIX el sistema continental europeo, con una fuerte influencia del proceso de codificación francesa, en el derecho público, especialmente en lo atinente a la organización institucional, el sistema federal de gobierno y la división de poderes ha seguido los lineamientos provenientes del constitucionalismo norteamericano.

Esto explica, en primer lugar, que la organización judicial es considerada tanto en la Constitución Federal argentina como en el de cada uno de las provincias como un verdadero Poder y no simplemente como un sistema de administración de justicia.

Ya en el primer período de la organización nacional, que se inicia con la Constitución Federal de 1853, la Corte Suprema de Justicia de la Nación, en un fallo del 5/12/1865, hizo suyo lo resuelto en la jurisprudencia norteamericana en el leading case "Marbury c. Madison" del año1803, referido a la doctrina de la supremacía y del control constitucionales(18).

En el precedente de la Corte Suprema argentina, se reivindicó expresamente la atribución que tienen y el deber en que se hallan los tribunales de justicia de examinar las leyes en los casos concretos que se traen a su decisión, para cotejarlas con la Constitución y así establecer, en el caso concreto, si guardan 
o no conformidad con ésta, y abstenerse de aplicarlas si las encuentran en oposición con ella.

En la organización institucional argentina -siguiendo el modelo norteamericano- existe el denominado "control difuso de constitucionalidad", en el sentido que el mismo es atribución de todo tribunal de justicia que entiende en casos concretos, sistema que difiere del llamado "control centralizado de constitucionalidad", como el consagrado, por ejemplo, en algunos países europeos, que asignan en forma exclusiva dicha tarea a las Cortes o Tribunales Constitucionales.

Ese "control de constitucionalidad difuso" en el Derecho argentino adquiere una enorme significación, sobre todo en períodos de vertiginosos cambios científico-tecnológicos y sociales, que se traducen en la necesidad de hallar soluciones justas y adecuadas, compatibles no sólo con el texto constitucional, sino con los valores y principios que informan al mismo.

A ello debe añadirse que, a partir de la reforma constitucional de 1994 (art.75 numeral 22), se reconoció a los once instrumentos internacionales y regionales en materia de derechos humanos -considerados como más importantes- “jerarquía constitucional". Esto nos permite afirmar que "el bloque de constitucionalidad"-que coincide con el criterio de "supremacía constitucional"- se integra ahora con el texto de la Constitución (federal y provincial), los principios y valores constitucionales, y el denominado derecho internacional de los derechos humanos, al cual se le reconoce jerarquía constitucional.

Esta doctrina de la "supremacía constitucional" tiene una significativa importancia en los denominados "procesos constitucionales de amparo" (conocidos como "tutela" en otros ordenamientos latinoamericanos), siendo dable recordar aquí que el amparo (consagrado también en la Convención Americana de Derechos Humanos, art.25), se concibe como un instrumento de garantía y tutela, rápida $\mathrm{y}$ eficaz de derechos y garantías de raigambre constitucional. Más aún, los propios textos constitucionales actuales permiten al juez o tribunal del "amparo" resolver en el caso concreto acerca de la incompatibilidad de alguna norma "infraconstitucional" (legislativa) con el contenido del "bloque de constitucionalidad" (declaración de inconstitucionalidad). Este desarrollo es particularmente importante al momento de resolver en el ámbito jurídico, respecto de los problemas bioéticos que se caracterizan por su complejidad y conflictividad. Ello, con frecuencia, puede determinar de hecho que antiguas normas legislativas atinentes al campo de las ciencias de la vida y del cuidado de la salud, resulten ahora incompatibles con los modernos desarrollos constitucionales y ante una más profunda captación de las exigencias de la dignidad humana como valor $\mathrm{y}$ principio fundante de todo el ordenamiento constitucional.

En el contexto de lo expuesto en párrafos precedentes, puede tal vez entenderse mejor la intervención de tribunales de justicia en la resolución de "casos bioéticos", de mayor o menor complejidad que, por regla general, plantean al mismo tiempo delicadas cuestiones de interpretación constitucional.

Más aún, cabe agregar que, por ejemplo, en la provincia de Buenos Aires -cuya población alcanza aproximadamente a $40 \%$ de la población del país- de acuerdo con su Carta Constitucional de 1994 y la legislación que regula en su ámbito la denominada "acción o recurso de amparo", cualquier juez o tribunal letrado de primera instancia con competencia en el lugar (cualquiera fuera su fuero) es competente para entender en esta acción 
constitucional. Esta amplitud ha sido en realidad favorecedora del acceso real y concreto a la justicia, en "casos bioéticos" en los que se ven afectados derechos fundamentales.

\section{Jurisprudencia relevante de la Corte Suprema de Justicia Federal de la República Argentina}

\subsection{Los Testigos de Jehová y la negativa a recibir transfusiones sanguíneas}

El 6 de abril de 1993 la Corte Suprema de Justicia Federal en la causa "Bahamóndez, Marcelo"7 tuvo oportunidad de intervenir, por primera vez, en un conflictivo caso bioético, caracterizado por un insalvable conflicto de valores, deberes y derechos, tanto desde una perspectiva bioética como jurídicoconstitucional. Dicho conflicto quedó planteado a partir del disenso de criterios entre el equipo médico -que estimó necesaria una transfusión sanguínea en un paciente Testigo de Jehová-, y la negativa de éste, fundada en sus convicciones religiosas.

Dentro de las circunstancias de hecho relevantes, cabe mencionar que Marcelo Bahamóndez, creyente del culto Testigos de Jehová, había sido internado en el Hospital Regional de la ciudad de Ushuaia al padecer una hemorragia digestiva, patología para la cual el equipo médico indica la realización de una transfusión sanguínea, a la cual el paciente se niega, por contrariar la misma las creencias que profesa.

\footnotetext{
Fallo publicado en las principales revistas jurídicas argentinas, entre otras en Jurisprudencia Argentina 1993-IV-555, con nota de Julio César Rivera, Bajo el título: Negativa a someterse a una transfusión sanguínea. También en la revista jurídica $L a$ Ley 1993. Buenos Aires-D-126. Finalmente en la revista $E l$ Derecho Buenos Aires T.153-249.
}

Las vicisitudes que el caso registrara en las distintas instancias judiciales hasta llegar finalmente a la CSJN, refleja las diversas perspectivas axiológicas en cuestión y, en última instancia, la prevalencia de una visión "paternalista" frente a otra respetuosa de la autonomía personal y de las convicciones íntimas de la persona involucrada.

En primera instancia, el juez interviniente autorizó expresamente la realización de las transfusiones sanguíneas que resultaran necesarias conforme a fundado criterio médico. En la instancia superior, en el caso la Cámara Federal de Apelaciones de Comodoro Rivadavia, se confirma la sentencia de la instancia anterior, por entender que la actitud de Bahamóndez, que ponía en peligro su vida, implicaba en realidad un "suicidio lentificado", que los jueces no podían ni debían convalidar.

El centro de la argumentación del Tribunal pasa por la estimación de la vida como bien supremo y absoluto, respecto del cual debe ceder el ejercicio de la libertad individual aun fundado en convicciones religiosas-, ya que el ejercicio de la libertad nunca puede tener un alcance tal de poner en peligro la propia vida, siempre en opinión de esta instancia judicial.

En representación del paciente Bahamóndez, el Defensor Oficial interpuso un recurso extraordinario ante la Corte Suprema Federal, contra lo decidido por la Cámara de Apelaciones, en la medida que ésta autorizaba una extracción sanguínea compulsiva que el paciente testigo de Jehová consideraba violatorio de sus derechos fundamentales. Se sostiene en el recurso que no es que el paciente deseara un suicidio, sino que, por el contrario, su deseo era vivir, pero respetando sus íntimas convicciones religiosas, siendo éstas las que, según el recurrente, debían prevalecer frente a un posible conflicto con la vida biológica. 
La sentencia de la Corte Suprema Federal debe ser calificada como verdaderamente paradigmática, hasta el punto tal que implicó de hecho el fortalecimiento decisivo de la línea jurisprudencial que priviligiaba en situaciones análogas la autodeterminación y la decisión en conciencia del paciente, en conflicto con la opinión médica, transformándose así en un verdadero "leading case".

Por razones procesales -cuyo análisis excede el ámbito de este trabajo-, tres de los nueve integrantes del Tribunal Superior no emitieron opinión sobre el fondo de la cuestión planteada, al estimar que el tema se había tornado abstracto toda vez que, a la fecha de la sentencia de la Corte y según información actualizada incorporada a la causa, en el tiempo transcurrido el paciente había recuperado su salud, sin que la proyectada transfusión sanguínea hubiese podido concretarse, debido a los recursos judiciales interpuestos por el propio Bahamóndez.

Los seis ministros de la Corte que emitieron su opinión votaron conformando tres bloques, que ponen en evidencia ciertos fundamentos comunes aunque, en cada caso, con particularidades y argumentos que, si bien diversos, resultarían en definitiva convergentes.

El primer "bloque", integrado por los ministros Fayt y Barra, coloca en el centro de su argumentación el respeto por la persona como valor fundamental, y señala que existen cuestiones de magnitud relacionadas con la esencia del ser humano, tales como el derecho a la vida, al cuerpo, a la libertad, a la dignidad, al nombre, a la intimidad, a la identidad personal $\mathrm{y}$ al respeto de la fe religiosa, desde que "el hombre es el eje y centro de todo el sistema jurídico y, en tanto fin en sí mismo, su persona es inviolable".

En otro párrafo de significativa relevancia para resolver el conflicto de valores, sostuvieron los nombrados jueces que el respeto a las personas es un valor fundamental jurídicamente protegido, con respecto al cual los restantes valores tienen siempre un carácter instrumental. Como corolario de ello, dignidad y libertad deben prevalecer sobre las formas de vida impuestas por la tecnología, reconociendo además, expresamente, al ser humano el "señorío a su vida, su cuerpo, su identidad, su honor, su intimidad y sus creencias trascendentes".

En el segundo bloque, que integraran los ministros Cavagna Martinez y Boggiano, se puntualizó ante todo que, no obstante haber recuperado su salud el paciente Bahamóndez y de haberse tornado desde el punto de vista procesal su caso "abstracto", la intervención de la Corte resultaba justificable, en atención a su misión de "Tribunal garante supremo de los derechos humanos", teniendo en cuenta que, dado el desarrollo rápido de situaciones como las allí tratadas, susceptibles de repetición en el futuro, una decisión del Alto Tribunal resultaba oportuna para garantizar en el porvenir el pleno respeto de derechos fundamentales en eventuales situaciones análogas.

El argumento central desarrollado por los nombrados jueces pasa ahora prioritariamente por el respeto a la libertad religiosa y la libertad de conciencia, a las que califican como derecho natural e inviolable. En cuanto a la libertad religiosa, se destaca su faz negativa, en el sentido de esfera de inmunidad de coacción, y su faz positiva, en el sentido de un ámbito de autonomía jurídica, con fundamento en la propia naturaleza de la persona humana.

Desarrollan también el denominado derecho a la objeción de conciencia, no sin remarcar expresamente que el paciente Testigo de Jehová, en realidad no busca el suicidio sino "mantener incólumes las ideas religiosas que profesa" estimando que en el caso debe prevalecer el respeto de la dignidad humana, aun cuando ello pudiera significar poner en peligro la vida de la persona. 
De manera complementaria se hace hincapié también en el hecho de tratarse aquí de una conducta autorreferente, de la cual el único eventual afectado sería el propio Bahamóndez, habida cuenta que su decisión no afectaba derechos de terceros. A modo de argumento englobante de los anteriores se enfatiza que todo el ordenamiento jurídico se asienta sobre el concepto mismo de persona y de los derechos emanados de su eminente dignidad.

Por último, el tercer "bloque" lo integraron los ministros Belluscio y Petracchi.

Ambos coincidieron con el voto conjunto anterior en admitir que la rapidez de las situaciones en el campo de la atención médica justificaba una intervención de la Corte ante la posibilidad cierta de su repetición en el futuro, en cuyo caso, y en razón de los tiempos que necesariamente demanda la tramitación en distintas instancias judiciales, probablemente, de llegar un nuevo caso a la Corte Federal, la decisión de ésta llegaría tarde: o bien, cabe acotar, se repetiría la afortunada situación de Bahamóndez, quien sanara sin la transfusión sanguínea, o se habría producido la muerte del paciente antes de que la Corte pudiera fijar su línea interpretativa constitucional.

Estimo que este voto conjunto es el más fuerte para una línea bioética, en cuanto respetuosa de la autonomía personal y con fuerte arraigo en el principio de "respeto por las personas" y de su inviolable dignidad.

En este orden de ideas, y con invocación expresa de normas y principios constitucionales, destacan que la propia Constitución protege jurídicamente un ámbito de autonomía individual y que "nadie puede inmiscuirse en la vida privada de una persona", sin su consentimiento o, en su caso, el de sus familiares autorizados, agregando que sólo por ley podría justificarse la intromisión, siempre que mediare un interés superior en resguardo de la libertad de los otros, la defensa de la sociedad o las buenas costumbres. En otras palabras, la restricción al derecho individual sólo reconocería como límite la existencia de un interés público relevante y cuando la restricción a un derecho individual sea la única forma de tutelar dicho interés, en el contexto del respeto a los derechos y valores sobre los que reposa una democracia constitucional.

Luego de reivindicar el "derecho a ser dejado a solas", se sostiene finalmente que no resulta justificada constitucionalmente una decisión judicial que autorizara a someter a una persona adulta a un tratamiento sanitario contra su voluntad, ya que debe privilegiarse la autonomía de la conciencia y la voluntad personal. Concluyen ambos jueces señalando que, en el caso planteado, no mediaba ningún interés público relevante que justificara la restricción a una decisión libre y autónoma del recurrente Bahamóndez.

Tal como surge de este breve y somero análisis de las tres posturas mencionadas, podemos observar la clara existencia de un fundamento común compartido, que pasa por el reconocimiento de la persona humana como fundamento del orden jurídico y por el respeto a la dignidad personal. Fuera de esta coincidencia, mientras que en el primer caso se asignó un rol prevalente a la cuestión atinente al respeto de la persona como valor fundamental y al señorío del hombre sobre su vida, su cuerpo, su intimidad y sus creencias trascendentes, en el segundo grupo el vector central pasaría por la libertad religiosa y el respeto a la objeción de conciencia, mientras que en el tercer "bloque" se reivindica con mayor fuerza el derecho a la autodeterminación, el respeto a la autonomía individual, restringiendo claramente la posibilidad de limitar tales derechos fundamentales sólo ante la existencia de un claro interés público relevante, compatible con una democracia constitucional. 
El valor de esta sentencia de la Corte Suprema Federal se halla en el hecho de haber originado en la jurisprudencia argentina, tanto a nivel de tribunales federales como provinciales, un cambio significativo, favorable en el caso a una orientación que abandonaba enfoques "paternalistas" que habían prevalecido en una jurisprudencia anterior vacilante, para privilegiar enfoques y criterios de decisión más compatibles con una perspectiva bioética fundada en el respeto a la dignidad y libertad personal.

Ciertamente que se trató aquí de un denominado "caso simple", es decir, que afectaba a una persona adulta, mayor de edad, "competente" en sentido bioético para la toma de decisiones, y "capaz" a la luz de las normas jurídicas vigentes.

La situación ciertamente se complejiza cuando no se reúnen todas estas condiciones. Los casos más frecuentes se vinculan con situaciones en las cuales un equipo médico -generalmente a través de la institución a la cual pertenece-, solicita una autorización judicial para realizar una transfusión sanguínea, considerada absolutamente necesaria para la preservación de la salud e incluso la vida de un paciente menor de edad, cuando los padres de ese menor, Testigos de Jehová, expresan su negativa para dicha prestación médica por razones religiosas.

En tales supuestos se puede hablar de una pacífica jurisprudencia nacional, que ha argumentado de la siguiente manera: si bien se respetan las creencias religiosas de los padres, se sostiene que el ejercicio de la patria potestad "como conjunto de derechos y deberes" (art.264 del Código Civil), no puede tener nunca un alcance tal de poner en peligro la vida misma del hijo, y que será éste en el futuro, alcanzada la edad adulta, quien adherirá o no libremente al culto que profesan sus padres.

Pueden presentarse, sin embargo, situaciones particularmente complejas cuando se tratare de "menores adultos" pero que aún no hubiesen alcanzado la mayoría de edad que el Código Civil argentino fija en los 21 años, situación que a su vez debe analizarse e interpretarse armónicamente con las previsiones de la Convención Internacional de los Derechos del Niño, que categoriza como "niño" a los menores que no hubiesen alcanzado la edad de 18 años.

Paralelamente, la misma Convención Internacional garantiza al niño su derecho a expresar su opinión libremente en todos los asuntos que le afecten, "teniéndose debidamente en cuenta las opiniones del niño en función de la edad y madurez" (art.12 de la Convención). Toda vez que esta Convención en el ordenamiento constitucional argentino reviste jerarquía constitucional, se torna necesario compatibilizar estas disposiciones con la legislación interna, especialmente las propias de la legislación civil.

Entendemos entonces que en estos casos debiera ponderarse cuidadosamente, y de manera fehaciente, la madurez emocional y psicológica del menor al momento de una toma de decisión atinente a su salud, máxime cuando la misma, eventualmente, puede poner en peligro su propia vida. No existirían aquí reglas fijas e inexorables, sino simplemente criterios de orientación que deberán tener en cuenta las circunstancias particulares de cada caso(19).

Otra situación particularmente crucial se presenta cuando la negativa a una transfusión sanguínea es sostenida, de manera firme por una paciente -en riesgo serio de vida- Testigo de Jehová, madre de pequeños hijos a su cargo, y cuando además esa misma determinación es apoyada por su cónyuge. En ese caso, un Tribunal Civil de segunda instancia de la ciudad de Buenos Aires, de manera coincidente con lo dictaminado por el Asesor de Menores, revocó una sentencia de primera instancia que, a pedido de las autoridades de un hospital, había autorizado una transfusión sanguínea compulsiva en la persona de un Testigo de Jehová, para lo cual el juez de grado había valorado 
particularmente la existencia de pequeños hijos a cargo de la paciente.

En definitiva, el Tribunal de la instancia superior privilegió el respeto a la libertad religiosa y la objeción de conciencia, aun frente a un grave peligro para la vida de la paciente internada ${ }^{8}$. Recordamos aquí que, en situaciones análogas, algunos fallos judiciales norteamericanos se pronunciaron en sentido contrario, priorizando en el caso el interés superior de los niños, frente al riesgo de perder a su madre.

\subsection{Anencefalia y autorización judicial para una inducción prematura del parto}

El autor de esta nota en el carácter de juez y por la vía de una acción de amparo, y previa realización de una serie de evaluaciones interdisciplinarias, incluyendo el dictamen de un Comité de Bioética, tuvo oportunidad de resolver favorablemente el primer caso planteado judicialmente -los precedentes conocidos hasta esa fecha habían concluido con sentencias denegatorias- en una causa resuelta el 30/12/96, en los autos "G.A., A.L. s/Acción de Amparo", sentencia inédita que quedara firme al ser consentida por todas las partes legalmente representadas en el proceso, incluyendo al Ministerio Público Fiscal y la Asesoría de Menores.

Sin embargo, sólo años después un caso similar llegó a conocimiento de un Tribunal Superior. Fue en el año 2000, se presentó ante la justicia local de la ciudad de Buenos Aires una petición, por la vía de amparo, en la cual, frente a un diagnóstico de certeza de la gestación de un feto anencefálico, sus progenitores solicitaron autorización judicial para una inducción prematura del parto, luego de una negativa del hospital público.

\footnotetext{
8 Ver revista El Derecho. Buenos Aires T.160-651, con nota favorable de Bidart Campos GJ. titulada: Derechos y valores convergentes en la objeción de conciencia en la transfusión de sangre: 654 y ss.
}

El expediente tuvo múltiples alternativas, primero por cuestiones de competencia y luego con relación al fondo de la petición formulada. Ésta fue denegada en primera instancia, resolución confirmada por un Tribunal de Apelación, por mayoría de votos (dos a uno), ante lo cual la mujer gestante y su marido interpusieron un recurso ante el Tribunal Superior de Justicia, máxima instancia de la justicia local de la ciudad autónoma de Buenos Aires.

Esta instancia superior, por amplia mayoría de votos (cuatro, con una sola disidencia), revocó la sentencia anterior e hizo lugar a la petición de amparo y, en consecuencia, autorizó expresamente a las autoridades y equipo médico del Hospital Materno Infantil "Ramón Sardá", para que se procediera a inducir el parto o, eventualmente, a practicar intervención quirúrgica de cesárea, conforme con las normas y protocolos médicos correspondientes y reglas de la lex artis, y según criterio que determinare el equipo terapéutico responsable. Se dejó expresa constancia que en caso de existir objeción de conciencia fundada por parte de algunos de los profesionales de la salud del hospital, que la misma fuera respetada, debiendo en tal caso la Dirección del Hospital disponer los reemplazos o sustituciones que correspondiera de manera inmediata y con carácter urgente.

Desde una lectura bioética, la sentencia del Tribunal Superior presenta aristas de particular interés. En primer lugar, por cuanto en la causa se había solicitado el dictamen del Comité Interdisciplinario de Bioética del propio hospital público, el cual fue cuidadosamente ponderado por los cuatro ministros que votaran favorablemente respecto del amparo promovido.

También resulta de peculiar significación que los jueces intervinientes recurrieran en sus argumentaciones a fundamentos y principios bioéticos, coadyuvantes y complementarios de 
normas y principios constitucionales atinentes al tema. No menos importante es la referencia a un concepto de salud integral, que incluye necesariamente -según se consigna en la sentencia- la salud psíquica de la mujer gestante y su grupo familiar, frente a informes periciales referidos a daños en la salud psíquica de la mujer.

Dictada la sentencia el 26/12/2000, el caso llegó a conocimiento de la Corte Suprema Federal, ante la interposición de un recurso extraordinario promovido por el Ministerio Público, en representación de la "persona por nacer", entendiendo que la sentencia ahora recurrida, al autorizar una inducción prematura del parto, afectaba el derecho constitucional a la vida del nasciturus.

La Corte Federal dictó sentencia en la causa el $11 / 01 / 2001^{9} \mathrm{y}$, por mayoría de votos, aunque con distinto fundamento que la instancia anterior, resolvió favorablemente respecto de la petición de amparo y, en consecuencia, autorizó al hospital a proceder a la inducción prematura del parto.

Dentro de los argumentos invocados por la mayoría del Tribunal se sostuvo que, en atención al tiempo de la gestación ( 8 meses a la fecha de la sentencia), no se trataba de un caso de aborto, entendiendo que en el caso "se verifica la situación paradojal de que, con el alumbramiento, aun rodeado de las máximas precauciones que puede proporcionar la ciencia médica, acontecerá la muerte del nasciturus. Llegar a ser un individuo en el mundo exterior significa cruzar un umbral que, en la especie, resulta insuperable; pues el mero hecho de atravesarlo provocará el deceso".

\footnotetext{
9 El texto completo de las sentencias tanto del Tribunal Superior de la ciudad de Buenos Aires como de la Corte Suprema Federal se publicó en la Revista Jurisprudencia Argentina Buenos Aires 2001; 6242, con notas de Morello títulada: "Entre la vida y la muerte" y Pedro F. Hooft, "La Bioética y el Derecho, aunados en mitigar el dolor humano: la anecefalia a la luz de los derechos humanos y de la Bioética".
}

En cambio, los dos ministros que votaron en disidencia consideraron que el respeto del derecho a la vida del nasciturus imponía aguardar la finalización del "curso natural" de la gestación, y que una inducción prematura del parto resultaría contraria a normas constitucionales y del derecho internacional de los derechos humanos, en particular la Convención Americana, en cuanto protege la vida humana "desde el momento de la concepción".

Con posterioridad, presentada en sede judicial una acción de amparo frente a una situación análoga, resuelta favorablemente en primera instancia por un Tribunal de Familia de la ciudad de Quilmes, provincia de Buenos Aires, la Suprema Corte provincial, por mayoría de votos revocó esta decisión y, en consecuencia, no autorizó la inducción prematura de un parto ante una gestación con diagnóstico de certeza de anencefalia, y ello no obstante haberse incorporado a la causa un fundado dictamen de un Comité de Bioética, favorable a la petición de la mujer gestante y su marido.

Recurrida la sentencia de la Corte provincial, la Corte Suprema Federal, reiterando su anterior jurisprudencia, revocó el pronunciamiento de la Corte de la provincia de Buenos Aires, uniformando de esa manera la interpretación constitucional en la materia.

Estas dos sentencias de la Corte Suprema de Justicia de la Nación han tenido el mismo efecto que una década atrás tuvo su fallo con relación a las transfusiones sanguíneas en las que mediaba objeción de conciencia (caso "Bahamóndez" ya citado), toda vez que durante el año en curso se han conocido distintos pronunciamientos judiciales, autorizando inducciones prematuras, ante diagnóstico de anencefalia. Más aún, en algunos casos, y previo dictamen de un Comité de Bioética, las propias instituciones de salud $\mathrm{u}$ hospitales autorizaron dicha prestación 
médica, sin necesidad de interposición de un recurso judicial.

Sin embargo, debe tenerse presente que en los fallos judiciales premencionados, además de la irreversibilidad de la patología que afectaba al feto anencefálico y de su absoluta incompatibilidad con la vida extrauterina, sumado al daño psíquico y eventual afectación de la salud física, se asignó importancia relevante a la "viabilidad" del feto, en razón del tiempo de la gestación a la fecha de las respectivas sentencias judiciales(20).

\subsection{La Corte Suprema y la "píldora del día después" ${ }^{10}$}

Una asociación civil ("Portal de Belén") promovió una acción de amparo contra el Ministerio de Salud de la Nación, el cual, a través de sus organismos técnicos, había autorizado la fabricación, distribución y comercialización del fármaco en venta bajo el nombre comercial de "imediat" como "anticonceptivo de emergencia".

La causa judicial fue iniciada en la provincia de Córdoba, por considerar la entidad accionante que el fármaco tendría efectos abortivos, al impedir el anidamiento del embrión en el endometrio y que, por lo tanto, la venta del fármaco en cuestión resultaba violatorio del derecho a la vida, consagrado tanto en la Constitución Nacional como en pactos regionales e internacionales en materia de derechos humanos y en la propia legislación civil.

En primera instancia hubo un fallo favorable a la pretensión de la accionante, y se dispuso ordenar al Ministerio de Salud dejar sin efecto la aprobación del fármaco cuestionado.

\footnotetext{
${ }_{10}$ Publicada en Revista Lexis Nexis Jurisprudencia Argentina 2002 (J.A.-2002-III- Suplemento del Fascículo No 1): 38-44.
}

La Cámara Federal de Apelaciones de Córdoba al hacer lugar a la apelación interpuesta por el Estado Nacional (Ministerio de Salud), dejó sin efecto la sentencia de primera instancia, entendiendo este Tribunal que la cuestión jurídica planteada excedía el ámbito restringido de la acción de amparo y que, al requerir de una mayor amplitud de debate y prueba, debería tramitarse a través de una acción judicial ordinaria.

La actora, "Portal de Belén", interpuso entonces un recurso extraordinario ante la Corte Suprema Federal. Ésta, por mayoría, el 05/03/2002 dictó sentencia, revocando el fallo de la Cámara cordobesa. Con cita del Pacto de San José de Costa Rica (art. 4 numeral 1), de la Convención Internacional sobre los Derechos del Niño (art. 6 numeral 1), normas de la Constitución Federal argentina y del Código Civil, consideró que la píldora en cuestión, por sus efectos que el Tribunal calificó como "abortivos", resultaba violatoria del derecho fundamental a la vida $y$, en consecuencia, ordenó al Estado Nacional dejar sin efecto la autorización referida a la fabricación, distribución y comercialización del cuestionado fármaco.

Conformaron la mayoría del Tribunal los Ministros Nazareno, Moliné O’Connor, Boggiano, López y Vázquez.

Votaron en disidencia, por una parte los Ministros Fayt y Bossert, quienes estimaron formalmente improcedente el recurso interpuesto por cuanto la resolución recurrida no era una sentencia definitiva o equiparable a tal, únicos supuestos en los cuales, en principio, entiende la Corte Suprema Federal.

Una segunda disidencia conjunta, la de los Ministros Belluscio y Petracchi, entendió -al igual que la Cámara de Apelaciones de Córdoba- que se trataba de una cuestión científicamente controvertida y que requería de un debate más amplio, con posibilidades 
probatorias que excedían el ámbito de conocimiento limitado propio de una acción de amparo, la cual requiere siempre, de manera ineludible, la existencia de una "arbitrariedad o ilegalidad manifiesta" que, a criterio de los nombrados jueces, no existía en el caso.

La sentencia en cuestión produjo un fuerte debate en los ámbitos jurídicos y bioéticos, con opiniones divergentes entre quienes se pronunciaron a favor o en contra de la decisión adoptada por la mayoría de la Corte Suprema Federal.

Entre las publicaciones coincidentes con el criterio de la Corte, y a la vez contrarias a la tesis que sustentara la Cámara Federal de Córdoba, cabe mencionar algunas notas publicadas en la Revista Jurídica "E1 Derecho". Con relación a la sentencia del Tribunal cordobés y que rechazara el amparo del "Portal de Belén", en un artículo de Guillermo Rivarola(21), se formula una fuerte crítica a dicha decisión judicial, sosteniendo el autor de manera enfática que, dado su efecto anidatorio, y por ende posterior a una eventual fecundación del óvulo, la píldora resulta abortiva y su utilización, por lo tanto, cercena el derecho fundamental a la vida.

En forma simultánea con la publicación de la sentencia de la Corte Federal en comentario, el constitucionalista Gregorio Badeni expresó su decidido apoyo al criterio de la mayoría del Alto Tribunal y, por lo tanto, contrario a la decisión del Ministerio de Salud que autorizara la comercialización y venta de la píldora. Fundamenta su postura desde la perspectiva "del derecho natural que regula la convivencia social y cuyo germen es el derecho a la vida", y entiende en concreto que el fármaco cuestionado, debido a su carácter antianidatorio y, por lo tanto, abortivo, resulta violatorio del derecho a la vida ${ }^{11}$.

\footnotetext{
${ }^{11}$ Badeni G. El derecho a la vida. El Derecho. 09/04/2002 (nota a fallo).
}

Desde el campo bioético y desde una perspectiva diversa, presenta interés el comentario al fallo del Dr. José Alberto Mainetti(22). Sostuvo el reconocido bioeticista que, a su juicio, se trata de un "tema abierto" que, desde la perspectiva bioética involucrada, ofrece al menos tres temas controvertibles relativos justamente a la "motivación de clausura" en la decisión judicial.

El primer aspecto, de orden jurídicoprocesal, se relaciona con la idoneidad del amparo para resolver una cuestión compleja y controvertida en el campo de la ciencia. La segunda cuestión es la atinente a la naturaleza de la píldora y la moralidad de la contraconcepción y del aborto, con relación a un fármaco calificado como de "contraconcepción de emergencia o postcoital" que impide el embarazo tras una relación sexual presuntamente fecundante. Es aquí donde Mainetti analiza distintas cuestiones implicadas en el tema y los debates referidos a los efectos del fármaco, observando que "los datos científicos no son conclusivos sobre el mecanismo de acción prevalente de la píldora, existiendo estudios que maximizan su virtualidad anovulatoria sobre la antinidatoria, con lo cual -agrega- la imprevisibilidad del efecto contraconceptivo o abortivo se traduce en una cuestión de conciencia dentro de la relación profesionalpaciente..."

El tercer aspecto del fallo que el autor considera controvertible es el relativo a la política pública que implica la prohibición de la llamada "píldora del día después". Es aquí que entiende que, desde la perspectiva bioética en una sociedad pluralista $\mathrm{y}$ democrática que se asienta en valores fundamentales compartidos y que, si bien es respetuosa de las convicciones personales, "no se identifica con una visión particular o confesional determinada, manteniendo la distinción clásica entre ética pública y ética privada". 
En conclusión, entiende el maestro Mainetti que la sentencia del Alto Tribunal Federal "considerada desde la Bioética como disciplina de ordenamiento moral de la revolución biológica y la nueva gestión del cuerpo humano, no parece ejemplar el papel de la Corte en la sociedad, si tal es el timonel de los cambios profundos en el orden social"12.

En publicaciones jurídicas vinculadas con el derecho de familia se han expresado, asimismo, perspectivas críticas respecto del fallo mayoritario de la Corte Suprema y desde una línea interpretativa que entiende que, desde el punto de vista científico, no es correcto hablar de aborto sino de contraconcepción de emergencia(23-25).

\section{Sentencias Judiciales dictadas por el autor de este trabajo, como juez y por la vía de la acción constitucional de amparo en "casos bioéticos"}

\subsection{Los primeros casos resueltos en 1991}

En el primer caso (resuelto el 03/05/91) ${ }^{13}$, se trataba de una cuestión que permitía una interesante lectura bioética, vinculada con un tema relacionado con los avances científicotecnológicos en la medicina ("problema emergente") que requería de una visión armónica del juego entre distintos principios bioéticos y su confrontación con normas legales y valores y principios constitucionales ${ }^{14}$.

Lo relevante del caso para un análisis de la Bioética en la jurisprudencia es que se trató de la primera sentencia judicial publicada en revistas especializadas, en la que un tribunal judicial, antes de resolver, requirió el dictamen de un Comité interdisciplinario de Bioética ${ }^{15} \mathrm{y}$ que, además de los fundamentos jurídicos, en la sentencia se recurriera asimismo a principios bioéticos.

Desde el punto de vista jurídico institucional nos encontramos ante un supuesto de verdaderos "derechos prestacionales" de un paciente enfermo renal crónico, con un cuadro de anemia crónica severa y que reclamaba al sistema de seguridad social la provisión de un nuevo medicamento conocido como "Eritropoyetina", medicación que permitía disminuir el número de sesiones de diálisis (que la obra social demandada costeaba), fármaco cuya autorización el sistema de seguridad había inicialmente otorgado, pero posteriormente denegado sin una justificación razonable.

El paciente consideró que dicha negativa se tornaba manifiestamente irrazonable y arbitraria e, invocando su derecho constitucional y legal a la atención a la salud, promovió la acción de amparo en sede judicial.

\footnotetext{
${ }^{12}$ Una ampliación de la controvertida cuestión, también desde la perspectiva bioética puede verse en: Manzini JL. La píldora del día después: ¿anti implantatoria? o ¿abortiva? Doctrina Judicial año XVIII, No $18,02 / 05 / 2002$ : 12-18 (nota a fallo). El autor plantea interrogantes referidos a la falta de una adecuada información respecto de los efectos de la píldora, necesaria para decisiones autónomas fundadas, en atención a las distintas lecturas morales posibles, a partir del momento considerado como de inicio de la vida humana. Relaciona también el tema con los dispositivos intrauterinos.

13 Navas, publicada entre otras en la revista jurídica El Derecho. 144-225, con nota de Bidart Campos GJ. titulada: Una prestación de salud justamente discernida por vía de amparo. También, en revista La Ley. 1991-D-77, con nota de Albanese S.: El amparo y el derecho adquirido a una mejor calidad de vida.
}

\footnotetext{
${ }^{14}$ Bidart Campos GJ. Los derechos no enumerados en su relación con el derecho constitucional y el derecho internacional. Lexis Nexis Jurisprudencia Argentina. 18/09/2002: 3 (J.A. 2002III-Fasc.12). Ha sido este reconocido constitucionalista quien, desde hace muchos años, viene bregando por una visión amplia de esta materia, que añade a los derechos normativamente consagrados los derechos innominados, que reenvían a la dignidad humana, a la personalidad humana, a la naturaleza humana y a la forma democrática de estado, agregando que la integración, frente a eventuales vacíos normológicos o carencias dikelógicas, se logra con el recurso a los principios y plexo de valores en los que se sustenta el orden constitucional democrático, todo ello a la luz de una interpretación dinámica.

15 En el caso, un Comité "Ad Hoc" de la Universidad Nacional de Mar del Plata.
} 
Efectuando una interpretación armónica entre los principios bioéticos y las normas, valores y principios constitucionales y legales aplicables, en la sentencia se ordenó a la obra social demandada (de la cual son afiliados obligatorios todos los empleados de organismos dependientes del gobierno de la provincia de Buenos Aires), a brindar la cobertura reglamentaria para el medicamento en cuestión.

Con posterioridad, otros tribunales acogieron peticiones similares, luego de lo cual las propias obras sociales o sistemas de seguridad oficiales incorporaron entre sus prestaciones la cobertura de "Eritropoyetina".

El segundo (sentencia dictada el 12/08/ $91)^{16}$ se relaciona con un tema que habría de generar algunas polémicas por una parte, pero una receptación posterior ampliamente mayoritaria en la jurisprudencia nacional. Se trataba de un pedido de autorización judicial para practicar -en un hospital público- una ligadura tubaria bilateral en una paciente que cursaba en ese momento su novena gestación, con ocho hijos anteriores, todos de su misma relación matrimonial.

Dentro del contexto fáctico relevante, además del número de hijos ya habidos, se valoró que dos de éstos presentaban serios problemas de salud, en medio de una situación socioeconómica precaria, a lo que debe añadirse que la mujer gestante presentaba, entre otras patologías, cuadros serios de hipertensión que se agudizaban durante el embarazo.

Se debió recurrir a la acción judicial en razón de la existencia de antiguas normas

\footnotetext{
${ }^{16}$ A. de A. M. L. En revista La Ley. 1991-E-565, con nota de Albanese S. La autorización judicial para una intervención quirúrgica frente a una situación límite. También en revista El Derecho. Tomo 145: 439, con nota de Bidart Campos GJ. bajo el título: La tutela médica del Estado providente y la privacidad matrimonial.
}

prohibitivas a nivel legal y en códigos deontológicos médicos, que literalmente limitaban la facultad del médico para practicar una intervención quirúrgica de estas características a situaciones en que mediaba una clara y precisa indicación terapéutica, y exclusivamente circunscripta al órgano reproductor.

La interpretación judicial que permitió superar este obstáculo ponderó en el caso la concurrencia de normas, principios y valores constitucionales, protectorios de la salud y calidad de vida de la persona involucrada y el bienestar del propio grupo familiar, aunado a una interpretación teleológica acerca de qué es lo que debía entenderse como indicación terapéutica: según la sentencia ésta no debía limitarse exclusivamente a la salud física (de un órgano), sino a un concepto de "salud integral", vinculado a "calidad de vida". Dicha perspectiva se amplía, asimismo, introduciendo un concepto de finalidad terapéutica preventiva o "de futuro", en el sentido que debía evitarse una situación que en el futuro (nuevo embarazo no deseado) podría afectar la salud y calidad de vida de la persona en cuestión -e inclusive de la propia persona por nacer-, ante el fracaso de distintas estrategias contraconceptivas utilizadas con anterioridad.

En definitiva, en base a una interpretación armónica de los principios bioéticos aplicables, y de las normas, principios y valores constitucionales, se autorizó la realización de la ligadura tubaria, a través del hospital público.

A partir de ese primer fallo se ha ido afianzando gradualmente una jurisprudencia más flexible, en una línea interpretativa de apertura. Más aún, en algunas jurisdicciones provinciales -téngase presente la forma federal de gobierno-, como por caso Mendoza y Río Negro, las leyes sobre "salud reproductiva" han incorporado previsiones atinentes al tema. 
En los numerosos casos resueltos por el autor de este trabajo en los últimos años, en acciones judiciales de amparo, se han ido plasmando criterios y pautas orientadoras, en base a las cuales habitualmente se concede este tipo de "autorizaciones" las que, hasta el momento, son requeridas por los hospitales públicos para llevar a cabo la prestación, no así en los centros privados.

Tales criterios podrían esbozarse esquemáticamente de la siguiente manera: a) el punto de partida será siempre el respeto a la dignidad y autonomía personal; b) en orden a ello, se adoptan los recaudos necesarios para asegurar la existencia de un verdadero consentimiento libre e informado, que incluye una audiencia personal del juez con la solicitante; c) se procura, en lo posible, incorporar al diálogo y toma de decisiones al marido o pareja estable conviviente, si existiere al momento del pedido, aunque se otorga importancia prevalente a la opinión fundada de la mujer; d) en las decisiones se trabaja con un concepto integral de salud vinculado a la noción de calidad de vida y de bienestar de la persona y del grupo familiar; e) lo anteriormente señalado implica, necesariamente, que el contexto socioeconómico y ambiental -muy particularmente en caso de mujeres multíparasofrezca un marco de referencia fundamental que se relaciona a su vez con el denominado "principio pro-minoris" que contempla el bienestar de los hijos ya habidos; f) una edad de la mujer mayor de 35 años es ponderada como circunstancia complementaria relevante, debido al riesgo genético aumentado en caso de futuras gestaciones; g) las razones de salud, vinculadas a nuevos embarazos no deseados, pueden ser por demás variadas y son valoradas siempre en conjunto con las demás circunstancias, en la situación concreta, siempre con respecto a un concepto integral de salud y calidad de vida; h) también se considera pertinente la valoración referida a dificultades anteriores con métodos contraconceptivos reversibles, tanto por su ineficacia en concreto como debido a posibles contraindicaciones médicas.

Otra indicación, ésta ya de carácter estrictamente médico, se vincula con la existencia de partos anteriores por cesárea, por significar -sobre todo a partir de la tercera cesárea- un riesgo aumentado para la mujer.

Dentro de los fundamentos normativos de las sentencias que reconocen el derecho de la mujer de acceder a esta prestación médica, amén de las ya mencionadas y el respeto a la esfera privada de las personas tuteladas constitucionalmente, cabe asimismo mencionar disposiciones de la Convención sobre la Eliminación de todas las Formas de Discriminación contra la Mujer ${ }^{17}$.

\subsection{Ligadura tubaria en paciente psiquiátrica severa, con finalidad terapéutica-preventiva ${ }^{18}$}

El amparo fue promovido en este caso por los profesionales de un servicio de salud mental de un hospital público. Se trataba de una paciente psiquiátrica severa, con declaración judicial previa de insania, cuya salud mental, que presentaba deterioros progresivos, se veía agravada reiteradamente ante embarazos no deseados y la posterior necesidad de separar al bebé de su madre, por cuanto ésta no se hallaba en condiciones de ocuparse de su crianza.

Las dificultades observadas por el Servicio de Salud Mental presentaban fundamentalmente

\footnotetext{
${ }_{17}$ Res.34/180 de la A.G. de la ONU, 18/12/79, instrumento que actualmente en la Argentina goza de jerarquía constitucional. Puede verse, para ampliación del tema: Morello AM, Morello GC. Los derechos fundamentales a la vida digna y a la salud. La Plata: Librería Editora Platense; 2002. En particular, el fallo judicial del autor, publicado en página 95.

${ }_{18}$ Servicio de Salud Mental del Hospital Interzonal General de Agudos de Mar del Plata, respeto de la paciente J.L.C., s/ Acción de Amparo, sentencia del 06/12/96. En Hooft PF. Bioética y Derechos Humanos. Temas y Casos. Buenos Aires: Editorial Depalma; 1999: 153. Con nota de Morello AM., bajo el título: Esterilización de incapaces, derechos fundamentales y garantías procesales.
} 
dos aristas complejas: a) que el embarazo, nacimiento y posterior separación del bebé de su madre aumentaba la angustia de la mujer, con una incidencia negativa comprobada respecto de la evolución de su patología psiquiátrica; b) la existencia de la gestación implicaba una contraindicación para la administración de determinados medicamentos que la salud mental de la paciente requería, por sus efectos nocivos sobre el feto en gestación.

El caso ofrecía no sólo las dificultades mencionadas al tratar el punto 2.1.) -segundo caso-, sino que se complejizaba seriamente en razón de la condición de paciente psiquiátrica declarada insana judicialmente, circunstancia que impedía contar con un verdadero consentimiento informado de la propia paciente.

Esto último obligó a recurrir a la figura del consentimiento subrogado ("proxy consent") para lo cual se tuvo en cuenta: a) la legitimación de los profesionales del servicio de salud mental para promover una acción judicial en atención al "mejor interés" de una paciente que no podía ser considerada como "persona autónoma"; b) se dio intervención a una Curadora Oficial, designada como representante legal de la paciente en el juicio de insania. No obstante tratarse ahora de "acciones personalísimas" para las cuales, en principio, el Curador no puede sustituir por sí la voluntad y la representación de quien se encuentra bajo curatela, se consideró, sin embargo, que su opinión, que en el caso resultó coincidente con la del servicio de salud mental, era importante para integrar dicha opinión en la conformación del consentimiento subrogado.

Se requirió, asimismo, dictamen de comités de Bioética, primero del propio hospital público y luego de la Universidad. Ambos informes interdisciplinarios, en base a una conjugación armónica de los principios bioéticos y teniendo en cuenta el criterio del mejor interés del paciente, coincidieron en considerar éticamente aceptable y conveniente para la propia paciente, la realización de una ligadura tubaria como único método eficaz en el caso concreto de evitar futuros embarazos no deseados.

En la extensa sentencia, que invocó, asimismo, un precedente jurisprudencial importante del derecho comparado (una sentencia del Tribunal Constitucional español sobre el mismo tema), se consideró jurídicamente procedente la petición de las autoridades del hospital, previo haber escuchado asimismo la opinión de la pareja estable conviviente -cuya capacidad de discernimiento se encontraba afectada por un problema de alcoholismo crónico-, información complementada mediante un exhaustivo informe social, y otro realizado por el Consultorio de Planificación Familiar del hospital, del cual se desprendía que anteriores alternativas contraconceptivas se vieron frustradas debido a la salud mental de la paciente.

Ciertamente que por la vía de la aplicación literal de normas legales vigentes, la decisión judicial debiera haber sido negativa respecto de la acción de amparo planteada. Sin embargo, en atención al principio de la "supremacía constitucional", comprensiva, como ya se viera, no sólo de normas sino también de valores y principios constitucionales, y a la luz de una interpretación comprensiva y armónica de principios bioéticos se arribó a una sentencia favorable a la petición formulada.

Es aquí importante destacar que la opinión del Ministerio Público (Fiscalía y Asesoría de Incapaces) resultó asimismo favorable para el otorgamiento de la autorización judicial que el propio hospital público había requerido.

En síntesis, ante el último diagnóstico autorizado respecto a la paciente que informaba acerca de una "psicosis delirante paranoidecrónica" con "pronóstico desfavorable. Tratamiento psicofarmacológico y psicoterapéutico" (sic.), y luego de una entrevista personal del juez de la causa con la paciente en el propio hospital donde se encontraba internada, 
se autorizó al hospital a llevar adelante la intervención quirúrgica-ligadura tubaria- la que se realizaría en forma conjunta con ocasión de realizarse otra cirugía prevista, por problemas urinarios.

\subsection{Autonomía personal, consentimiento informado y el derecho de rehusar una intervención médica ${ }^{19}$}

Se trataba en el caso de un paciente con un cuadro de diabetes severa, con una segunda intervención quirúrgica legalmente calificada de "mutilante" (amputación del miembro inferior debido a la isquemia vascular de miembro inferior izquierdo, con necrosia en ambos dedos, celulitis y edema en el pie), la que debía llevarse a cabo en el hospital público, a tres meses de la amputación de la pierna derecha.

Si bien el paciente, desde el punto de vista formal, al reingreso al hospital había firmado las planillas correspondientes al "consentimiento informado", al momento de ser trasladado al quirófano para llevar a cabo la amputación prevista, manifestó de viva voz su oposición, lo que generó desorientación en el equipo médico interviniente.

Se originaba en ese momento un serio conflicto de derechos, deberes y valores: desde el punto de vista médico, la intervención quirúrgica era considerada estrictamente necesaria para intentar salvar la vida del enfermo, pero dicha indicación médica entraba ahora en conflicto insuperable con la manifestación de voluntad inequívoca del paciente respecto de esa amputación.

\footnotetext{
${ }_{19}$ Parodi (sentencia de fecha 18/09/95). En Hooft PF. Bioética y Derechos Humanos. Temas y Casos. Buenos Aires: Editorial Depalma; 1999: 217. Con nota de Bidart Campos GJ., bajo el título: La salud propia. Las conductas autorreferentes y el plexo de derechos en el sistema democrático.
}

Frente a esta situación fueron las autoridades del hospital quienes hicieron la presentación judicial con el fin de que se resolviese cuál era la conducta a seguir en el caso, ante las fundadas dudas que, desde lo legal, presentaba el caso.

La presentación originó diversas medidas, decretadas con la urgencia que el caso requería: se solicitó de inmediato un informe al servicio de salud mental del cual resultó que el paciente, al momento de manifestar su voluntad contraria a la intervención quirúrgica, se hallaba en el pleno uso de sus facultades mentales y en conocimiento de las posibles consecuencias de su decisión, a pesar de lo cual rehusó de manera clara y firme el tratamiento quirúrgico propuesto.

Además de una evaluación médica, psiquiátrica y social actualizada, se requirió dictamen al Comité de Bioética del hospital. Al producirse éste, la cuestión ya presentaba una complejidad mayor, por cuanto en horas, a causa de la evolución del cuadro del paciente, éste ya no podía expresarse con lucidez. Ante ello, el Comité priorizó la voluntad autónoma del paciente expresada con anterioridad evaluada en el dictamen del servicio de salud mental-, estimando que, en consecuencia, debía respetarse la decisión del enfermo en cuanto expresó su negativa respecto a la amputación en cuestión.

Además de haberse documentado la opinión de profesionales de enfermería, quienes pudieron corroborar manifestaciones atribuidas al paciente coincidentes con su negativa a la intervención médica proyectada, la última medida consistió en la presencia personal del juez en el hospital acompañado de perito psiquiatra oficial.

En la sentencia dictada con la premura que el caso requería, se sopesaron cuidadosamente tanto los principios constitucionales y legales como los bioéticos involucrados, con una fuerte reivindicación de respeto a la autonomía y 
dignidad personal y a la doctrina del consentimiento informado.

Partiendo del reconocimiento de la existencia de conductas autorreferentes, constitucionalmente amparadas, la jurisprudencia de la Corte Federal sentada en el caso "Bahamóndez", y con expresa invocación de la "dignidad humana" como valor fundante y el derecho a la privacidad ("right of privacy"), se resolvió que el hospital debía abstenerse de realizar la intervención quirúrgica. Sin embargo, se dispuso al mismo tiempo que debería continuar brindándosele al enfermo todos los cuidados que su salud requería, con el fin de resguardar su dignidad personal $\mathrm{y}$, en última instancia, su derecho a "morir con dignidad".

\subsection{Bioética y trasplante de órganos ${ }^{20}$}

En el plano jurídico, Argentina cuenta con una legislación sistemática en materia de ablación y trasplante de órganos desde el año 1977 , siendo que la ley actualmente vigente $\mathrm{n}^{\circ}$ 24.193 se encuentra vigente desde 1993.

No obstante tratarse de un ordenamiento que, en general, ha sido valorado muy positivamente por la crítica especializada, suelen presentarse situaciones complejas que requieren de un abordaje desde la perspectiva bioética y constitucional en la búsqueda de soluciones justas para el caso concreto.

Dentro de aquellas situaciones que de algún modo van más allá de las múltiples cuestiones sistemáticamente abordadas en la legislación en vigor, se encuentra la que fuera resuelta por

\footnotetext{
${ }^{20}$ Revista El Derecho; T.163-973 (1995), con nota de Bidart Campos GJ. Donación y trasplante de órganos entre excónyuges divorciados vincularmente. Ver además Hooft PF. Bioética y Derechos Humanos. Temas y Casos. Buenos Aires: Editorial Depalma; 1999: cap.IV, Segunda Parte. 191. Con nota de Tinant EL. Bajo el título: Bioética, amparo y un nuevo caso de trasplante de órganos a la luz de la interpretación previsora.
}

sentencia, por la vía de la acción de amparo, en el año 1995.

En relación con el criterio rector de la ley en el tema referido a ablación y trasplante de órganos "inter vivos", se halla el de haber establecido un criterio rígido, fundado en estrictos lazos de parentesco, taxativamente enumerados, con la finalidad de evitar una eventual comercialización de órganos que pudiera eventualmente ser presentada bajo la apariencia de un acto de "donación" ("dación" en la terminología de la ley).

Ahora bien, el caso judicial se suscita ante el acuerdo entre personas anteriormente relacionadas por el vínculo del matrimonio divorciados vincularmente- (y con un hijo en común), en el sentido que la mujer brindaba su expreso consentimiento para "donar" un riñón a favor de su ex-cónyuge, enfermo renal crónico terminal.

La ley autoriza dicha ablación y trasplante entre cónyuges. Como nada dice respecto de "ex-cónyuges" divorciados, y en razón del criterio restrictivo en cuanto a la donación de órganos inter vivos, el centro hospitalario en el cual se llevaría a cabo la intervención médica entendió que el caso no encuadraba en las normas legales vigentes, sugiriendo expresamente a los interesados tramitar una autorización judicial.

Dentro de las circunstancias particularmente relevantes valoradas con miras a la resolución del caso se encontraban las siguientes: a) si bien el eventual receptor se encontraba inscripto desde el año 1989 en el organismo público que regula la materia, con miras a la posible obtención de un riñón de donante cadavérico, su posibilidad concreta de acceder al mismo era ínfima en razón de su grupo sanguíneo B negativo; b) debía evaluarse la situación de la hija menor de ambos por cuanto la enfermedad renal que padecía su padre tenía origen genético, y ello importaba que la hija menor 
tuviese un $50 \%$ de probabilidad de ser también portadora del gen defectuoso y poder desarrollar en el futuro la misma patología que aquejaba a su progenitor; c) en una decisión ética ejemplar la madre de la niña expresó su voluntad en el siguiente sentido: que se evaluara previamente el problema genético con relación a su hija, por cuanto en caso de ser ésta portadora del gen defectuoso, preservaría su riñón para el futuro, para un eventual trasplante a favor de la hija, pero de descartarse esta situación, quería donar uno de sus riñones a favor de su ex-marido, alegando que para ella era muy importante que su hija pudiera contar con su padre con una mejor perspectiva de vida y de calidad de vida.

Se solicitó también un dictamen al Comité de Bioética de la Universidad, y en base a una valoración armónica y sistemática, tanto de las circunstancias fácticas como de las normas, valores y principios, tanto constitucionales como legales aplicables, en consonancia con análoga interpretación de los principios bioéticos, se consideró procedente resolver favorablemente la cuestión planteada, la sentencia judicial autorizó la eventual ablación y posterior trasplante de riñón.

Entre otras consideraciones se asignó en el fallo particular importancia al valor "solidaridad" que, en palabras de Karen Vasak, da sustento a los denominados derechos humanos de la tercera generación. Desde una lectura bioética y jurídico-constitucional se priorizó el respeto a la autonomía y dignidad personal y a la regla del consentimiento informado que, en el caso, satisfacía todos los recaudos que permitían hablar de un consentimiento esclarecido, verdaderamente libre.

En un caso posterior, resuelto el 28/06/96, el mismo juzgado autorizó la ablación y trasplante de riñón entre dos hermanos por parte de padre, quienes, en razón de no haber sido reconocidos por su progenitor como tales en vida, no podían acreditar su relación de parentesco mediante sus respectivas partidas de nacimiento y/o documentos de identidad personal.

Durante la sustanciación del proceso, mediante prueba fehaciente recepcionada, se pudo acreditar lo que jurídicamente se conoce como "posesión de estado" (hay posesión de estado, cuando alguien disfruta de un estado de familia determinado con independencia del título sobre el mismo estado). En consecuencia, conforme a la legislación civil, dicha "posesión de estado", al haber sido reconocidos públicamente en su medio social y familiar como "hermanos", implicaba gozar del mismo valor que de haber sido reconocidos por parte del progenitor ya fallecido.

Habiendo mediado dictámenes periciales favorables, incluyendo opinión fundada del Ministerio Fiscal y una exhaustiva evaluación psicológica que permitió dar por presente un consentimiento verdaderamente informado, libre y esclarecido, y priorizando nuevamente el valor "solidaridad", se resolvió favorablemente respecto de la presentación, autorizando al hospital a llevar adelante la ablación y posterior trasplante, tal cual, en forma conjunta lo habían pedido los dos hermanos.

\subsection{Derecho a la salud integral: anencefalia y autorización judicial para una inducción prematura del parto. Conflicto de derechos y de valores}

Para una visión más amplia de las cuestiones bioéticas y jurídicas presentes al momento de resolver respecto de una interrupción, o no, de un embarazo frente a un diagnóstico de certeza de anencefalia, me remito a un trabajo anterior(22).

El primer caso -inédito- fue resuelto el 30/12/ $96^{21}$, seguido de otras sentencias igualmente inéditas; entre éstas, se dictó un nuevo fallo, con fecha $23 / 05 / 01^{22}$. 
Con fundamento en amplia y actualizada bibliografía bioética y médica, se estimó particularmente significativo al momento de la toma de decisión los siguientes aspectos: a) la existencia de diagnósticos de total certeza; b) la absoluta incompatibilidad del feto anencefálico con la vida extrauterina siempre y con la vida intrauterina a menudo; c) la ponderación de la salud integral, abarcadora de la salud psíquica, como un verdadero derecho humano fundamental y, por lo tanto, constitucionalmente tutelado; d) los riesgos que para la salud de la madre implica en un porcentaje importante de casos, la prolongación del embarazo, sobre todo a partir del tercer trimestre; e) la afectación de la salud psíquica, que puede traducirse en grave daño psíquico, a causa de la continuación de un embarazo sin futuro, con las angustias propias de una situación que tan gráficamente calificara James Drane como propias de un funeral prolongado $(26,27)$.

En ese contexto, en el caso decidido se estimó que el derecho constitucional a la vida del nasciturus no se veía afectado por una inducción prematura del parto, dado que, finalmente, su muerte sería siempre el resultado irremediable de su grave patología congénita para la cual, en el actual estado de la ciencia, no existe terapia posible alguna.

En la sentencia se asigna importancia suma al respeto de la conciencia moral de las personas involucradas, en un proceso de deliberación que parte a su vez de un profundo respeto por la vida y la dignidad del ser humano y, al mismo tiempo, de la protección de la salud como valor y derecho fundamental(28).

\footnotetext{
${ }^{21}$ Ver apartado 1.2 del presente trabajo.

${ }^{22}$ N., P. K. Publicada en revista Lexis Nexis Jurisprudencia Argentina 12/12/01. Número especial de Bioética Primera Parte. (J.A.2001-IV-fasc. N $^{\circ} 11$ ): 61. Con nota de Tinant EL. bajo el título: Anencefalia tecnociencia y autorización judicial de terapia límite.
}

La sentencia finalmente autoriza al hospital público a practicar una inducción anticipada del parto o la realización de una operación cesárea según las reglas de la lex artis y criterio terapéutico del equipo responsable, agregando que, en caso de mediar objeción de conciencia fundada de algún profesional del equipo interviniente, se respete la misma, debiendo en su caso la institución de salud proceder a los reemplazos pertinentes.

\subsection{Cambio de sexo: Pseudohermafroditismo y Transexualidad}

El primer caso resuelto ${ }^{23}$ fue de pseudohermafroditismo. Se trataba de una persona asentada en su partida de nacimiento como de sexo masculino, con prenombres correspondientes al mismo sexo y documentos de identidad concordantes con los datos anteriores. Desde el punto de vista médico presentaba órganos genitales externos ambiguos, genéticamente de sexo masculino, aunque con caracteres sexuales secundarios femeninos, por ejemplo voz y desarrollo mamario. Desde la perspectiva psicológica, sus vivencias, emociones y maneras de relacionarse eran típicas del género femenino, lo cual llevó a los peritos informantes en la causa a coincidir en que se estaba en presencia de un sexo psico-social netamente femenino.

Esta discordancia entre el sexo legal (y cromosómico) respecto del sexo psico-social fue vivenciada por la persona desde su más corta edad. Esto le generó, sobre todo a partir del momento en que iniciara su período de escolaridad, serias situaciones de discriminación, las que se vieron acentuadas durante los años en que cursara sus estudios universitarios.

\footnotetext{
${ }^{23}$ M.M.A. Sentencia de fecha 07/11/1997. En Hooft PF. Bioética y Derechos Humanos. Temas y Casos. Buenos Aires: Editorial Depalma; 1999: 259.
} 
Luego de evaluaciones médicas, psiquiátricas, psicológicas e informes sociales, se incorporó a la causa el dictamen de un Comité de Bioética. Pudo apreciarse una marcada coincidencia desde las distintas perspectivas disciplinarias involucradas en cuanto a la conveniencia -en protección de la dignidad y salud integral de la persona solicitante- de acceder a su pedido de "cambio de sexo" (en realidad, en este caso, de determinación de un sexo ambiguo), que requería de la realización de una intervención quirúrgica femeneizante.

Los fundamentos constitucionales y bioéticos en los que se sustentara la sentencia, que acogió favorablemente la petición de amparo, involucraban -tal como lo destacara el catedrático Carlos Fernández Sessarego ${ }^{24}$ - la remisión a la idea de dignidad de la persona humana, la libertad, el derecho a la identidad personal, el derecho a no ser discriminado y el derecho constitucional a la salud en sentido integral. Se entendió así en la sentencia que la intervención quirúrgica cuya autorización judicial se requería -acompañada de un cambio de prenombres masculinos por otros propios del género femenino, rectificación de la partida de nacimiento, expedición de nuevos documentos de identidad personal $\mathrm{y}$, por último, la correspondiente rectificación en su título profesional universitario-, constituía la única vía adecuada para poner fin a una prolongada situación de discriminación, permitiendo, en cambio, que la persona en cuestión fuese realmente reconocida en su dignidad, identidad personal e identidad sexual real, para tener de esa manera acceso a una adecuada calidad de vida que implicara, al mismo tiempo, la protección de su salud integral.

Cabe finalmente destacar que dictaminó favorablemente en el proceso el Ministerio Público Fiscal, quedando firme la sentencia judicial en primera instancia.

\footnotetext{
${ }^{24}$ Fernández Sessarego C. Una excelente sentencia sobre un caso de intersexualidad. Comentario a sentencia judicial mencionada en la cita anterior: 260/274.
}

Según pudo comprobarse posteriormente, la intervención quirúrgica se llevó a cabo con todo éxito, y cumplidas las demás medidas ordenadas en la sentencia, la persona que recurriera a la justicia, pudo realmente reencausar su vida, lograr una nueva inserción social acorde con su "verdad cotidiana" e inclusive mejorar la relación con su progenitor, la que antes siempre se había visto afectada debido a la ya mencionada discordancia entre el sexo legal y el sexo cotidiano y psico-social.

Un segundo caso $^{25}$ correspondió a una situación típica de transexualidad, que había afectado por vida a una persona que al momento de iniciar la acción judicial contaba con 59 años de edad.

Registrada en su partida de nacimiento como de sexo masculino, y con nombres correspondientes a tal circunstancia, desde su más tierna infancia sufrió internamente una absoluta discordancia entre el sexo legal masculino y sus sentimientos, emociones, vivencias $\mathrm{y}$, en general, modos de comportamiento que la sociedad estima como propias del sexo femenino.

Todo esto había dado lugar a situaciones de permanente discriminación, ya manifiestas durante los años en que cursara la escuela primaria, problemas acentuados durante su período de escolaridad media. Además, hubo otras circunstancias familiares particularmente complejas, traducidas en una muy mala relación con quien era su madre legal (aunque ya en su adolescencia supo que no era en realidad su madre biológica), vínculo conflictivo que hizo eclosión a los 16 años de edad, al fallecer su padre.

\footnotetext{
25 J.C.P. Sentencia de fecha 19/07/2001, publicada en Revista Jurídica Lexis Nexis Jurisprudencia Argentina. 19/12/2001. Número especial Bioética. Segunda Parte. (J.A.2001-IVfasc.12):46. Con nota de Graciela Medina y Héctor Fernández. p.55.
} 
Años después, debido a su aspecto físico exterior y modo de comportarse femenino, fue descalificada al momento de ser sometida a una revisión médica para el servicio militar obligatorio. Esto agudizó su rebeldía frente a una sociedad que no la aceptaba y llevó a la persona a destruir su documento de identidad, el cual recién tramitó nuevamente 40 años después para poder iniciar el trámite judicial.

Al evaluar las circunstancias trágicas de su vida, se consignó en la sentencia que dicha persona había padecido una verdadera muerte civil: la discordancia entre su sexo legal y el psico-social, el no poder presentar su documento de identidad con un prenombre masculino cuando toda su fisonomía y modos de relacionarse eran femeninos significó, además, que nunca pudo durante su vida de relación desempeñar un trabajo remunerado que estuviese registrado legalmente. Estuvo por lo tanto marginada de todo el sistema de seguridad social y de los servicios de salud que pudieran haberle correspondido a causa de los trabajos realizados, todo lo cual no hacía sino potenciar la situación de grave discriminación que la afectara durante tantos años.

Además de las evaluaciones médico forenses, psiquiátricas y psicológicas, se requirió también un dictamen interdisciplinario de un Comité de Bioética ${ }^{26}$, lo que permitió incorporar al expediente opiniones sustancialmente coincidentes en cuanto a la necesidad humana y la conveniencia social de acceder a la petición de "cambio de sexo".

Se consideró probado en la sentencia que en el caso, entre otros aspectos, se encontraba afectado el derecho a la salud integral de la persona requirente, el respeto a su dignidad, identidad personal e identidad sexual, todo ello

\footnotetext{
${ }^{26}$ En el caso intervino el Comité de Bioética de la Asociación de Genética Humana de la ciudad de Mar del Plata.
}

vinculado estrechamente con el concepto de calidad de vida. Asimismo, se estimó particularmente relevante anudar el caso al principio constitucional de "no discriminación", entendiendo que acceder a lo peticionado judicialmente constituía, en el caso, la única vía apropiada para poner fin a tan prolongada discriminación y permitir, a partir de ahora, que la persona pudiese contar con una tutela real y efectiva de sus derechos fundamentales, al ser reconocida en su verdad existencial.

Aunando principios bioéticos, normas, principios y valores constitucionales y aportes provenientes del derecho internacional de los derechos humanos, se estimó legalmente procedente el amparo promovido $\mathrm{y}$, al hacer lugar al mismo, se dispuso la rectificación de la partida de nacimiento, el cambio de prenombres (los de sexo masculino fueron sustituidos por otros propios del género femenino) disponiéndose asimismo la expedición de nuevos documentos de identidad, autorizándose al mismo tiempo la realización de una intervención quirúrgica femeneizante que, poco tiempo después, se llevó a cabo con excelentes resultados.

\section{Reflexión Final}

Muy brevemente, el propósito de este trabajo ha sido ofrecer un nuevo enfoque posible respecto de los vínculos entre Bioética y Derecho, desde la perspectiva de un "Derecho en acción", es decir de un Derecho vivo en la sociedad y atento a las hondas transformaciones que afectan a la sociedad contemporánea. Para ello se ha recurrido al análisis crítico de una serie de "casos bioéticos" -que por cierto no agota el inmenso número de situaciones posible- con una "visión integradora", desde nuevas formas de juridicidad, y con una propuesta a favor de una posible y fructífera complementación entre Bioética y Derechos Humanos. Corresponderá finalmente al lector evaluar si este propósito ha sido alcanzado. 


\section{Referencias}

1. Gracia Guillén D. De la Bioética Clínica a la Bioética Global. Acta Bioethica 2002; 1: 30.

2. Lolas Stepke, F. Ciencias Sociales Empíricas y Bioética. Acta Bioethica 2002; 1: 49.

3. Broekman JM. Definición y contexto legal de la Bioética. Jurisprudencia Argentina. Número especial Bioética. Buenos Aires 1998; 6113: 4.

4. Hooft PF. Bioética y Derechos Humanos. Temas y Casos. Buenos Aires: Editorial Depalma; 1999: 101.

5. Mainetti JA. Bioética Sistemática. La Plata: Editorial Quirón; 1991: 11.

6. Mandrioni HD. Pensar la Técnica. Filosofia del Hombre Contemporáneo. Buenos Aires: Editorial Guadalupe; 1976: 123.

7. Broekman JM. Interwinements of Law and Medicine. (Leuven Law Series 7) Leuven: Leuven University Press; 1996.

8. Van Neste FSJ. Recht en Ethiek ten aanzien van de Geneeskunde. Ethiscke Perspecdieven marzo 1993; Centrum voos Biomediche Ethiek en Recht. Univ. Católica de Lovaina; 3: 8-15.

9. Van der Burg, Gezondheitsrecht en bio-ethiek: op een nieuwe verhouding. Rechtsfilosofie en Rechtstheorie. 1996-3.

10. Gafo J. Diez palabras clave en Bioética. 3era. Edición. Pamplona: Editorial Verbo Divino; 1997: 11.

11. López Aspitarte E. Ética y Vida. Desafios Actuales. 3ra.Edición. Madrid: Ediciones Paulinas; 1990: 5.

12. Lolas Stepke F. Empirical Social Science Studies and Bioethics. En: Lolas F, Agar L, eds. Interfaces Between Bioethics and the Empirical Social Sciences. Santiago de Chile: Programa Regional de Bioética OPS/OMS; 2002: 11.

13. Broekman JM. Bioética con rasgos jurídicos. Madrid: Editorial Dilex S.L.; 1998: 27.

14. Drane JF. What is Bioethics? A History. En: Lolas F, Agar L, eds. Interfaces Between Bioethics and the Empirical Social Sciences. Santiago de Chile: Programa Regional de Bioética OPS/OMS; 2002:15.

15. Bidart Campos GJ. Las transformaciones del derecho en la postmodernidad. Buenos Aires: Editorial Ediar; 1999.

16. Nys H. La Convención Europea de Bioética. Objetivos, Principios rectores y posibles limitaciones. (Traducción de Hooft PF.) Jurisprudencia Argentina Buenos Aires 2000; 6181: 7-16.

17. Sá E. Biodireito. Río de Janeiro: Editorial Lumen Juris; 1999. 
18. Bidart Campos GJ. Manual de la Constitución reformada. Tomo I. Buenos Aires: Editorial Ediar; 1996: 335.

19. Lavalle OO. Consentimiento informado en adolescentes. Jurisprudencia Argentina. Número especial Bioética. Buenos Aires 2000; 6218: 56.

20. Hooft PF. Anencefalia: consideraciones bioéticas y jurídicas. Acta Bioethica 2000; 2: 265.

21. Rivarola G. La píldora del día después: ¿Anticonceptiva o abortiva”? El Derecho 06/10/2000 (nota a fallo). Universidad Católica Argentina "Santa María de los Buenos Aires.

22. Mainetti JA. Comentario a la sentencia de la Corte Suprema sobre la píldora del día después. Lexis Nexis Jurisprudencia Argentina. 03/07/2002: 44.

23. Medina G. Bioética, Libertad Sexual y Derecho. Derecho de Familia. Bioética y Derecho de Familia; 21: 103 .

24. Basterra MI. Prohibición de la píldora del día después; un lamentable retroceso del principio de autonomía personal. Derecho de Familia. Bioética y Derecho de Familia; 21: 198.

25. Galimberti D. La anticoncepción de emergencia. Derecho de Familia. Bioética y Derecho de Familia; 21:210.

26. Drane JF. Anencephaly and interruption of Pregnancy; Policy Proposals for HELS. H.E.C. Forum; 4 (2). Netherlands: Ed.Kluwer Academic Publishers; 1992: 103-119.

27. Giberti E. Anencefalia y Daño Psíquico en la madre. Derecho de Familia. Bioética y Derecho de Familia; 21: 43-63.

28. Gómez C. Conciencia Moral. En: Cortina A, coord. Diez Palabras Clave en Ética. Navarra: Editorial Verbo Divino: 17-69. 